\title{
Drug Utilisation Pattern in Ear, Nose and Throat Inpatient Department using WHO Prescribing Indicators
}

Deependra Prasad Sarraf, ${ }^{1}$ Bajarang Prasad Sah ${ }^{2}$

\begin{abstract}
${ }^{1}$ Department of Clinical Pharmacology and Therapeutics, B. P. Koirala Institute of Health Sciences, Dharan, Nepal ${ }^{2}$ Department of Otorhinolaryngology and Head and Neck Surgery, B. P. Koirala Institute of Health Sciences, Dharan, Nepal
\end{abstract}

Introduction: Assessment of drug utilisation pattern (DUP) based on World Health Organisation (WHO) drug prescribing indicators would enhance the standards of patient care at all levels of the healthcare. It helps to improve the quality of life in developing countries like Nepal.

Objective: To assess DUP in patients admitted in ear, nose and throat inpatient department at a tertiary hospital in Eastern Nepal using the WHO prescribing indicators.

Methods: A hospital based cross-sectional descriptive study was carried out in 96 patients in ENT department of a tertiary care teaching hospital from February-April 2019. Pre-designed proforma was used to collect the relevant data from the medical case sheets and drug charts. Descriptive statistics were calculated using Microsoft Excel 2010.

Results: Out of 96 patients, 52 (54.17\%) were female. Most of the patients (46, 47.18\%) were prescribed four drugs. Combination of Ibuprofen and Paracetamol $(77,19.74 \%)$ was the commonest prescribed drug. Ceftriaxone $(62,63.92 \%)$ was the most frequently prescribed systemic antibiotic. The average number of drugs per prescription was 4.06. None of the drugs were prescribed by generic name. Out of 360 drugs, only 118 (30.26\%) were prescribed from National List of Essential Medicines (NLEM) and 117 (30.00\%) drugs were fixed drug combinations. Ninety two (95.83\%) patients had been prescribed at least one antibiotic.

Conclusions: The prescribing practices of essential medicines, generic drugs, antibiotics and injectable drugs showed deviation from the standard recommended by the WHO. The prescribers should be motivated to enhance prescription of drugs by generic names and from NLEM.

Key-words: Drug utilisation; essential medicines; prescribing.

Submitted: May 31, 2021 Accepted: June 8, 2021

Published: June 28, 2021

\section{INTRODUCTION}

According to the WHO, more than $50 \%$ of all medicines are prescribed, dispensed or sold inappropriately. ${ }^{1}$ The problem is exacerbated in the developing countries like Nepal due to the limited resources and inadequate drug and hospital policy. ${ }^{2}$ Drug utilisation research (DUR) is the marketing, distribution, prescription and use of drugs in a society, with special emphasis on the resulting medical, social, and economic consequences. It helps to determine the rationale drug therapy and also provides evidence based guidance for making various policies at hospital setting. ${ }^{3}$ It forms the basis for making amendments in the drug dispensing policies at local and national levels and hence it holds a crucial place in clinical practice. ${ }^{4}$ There have been various DUR conducted on specific populations and in varied settings in Nepal..$^{-8}$ However, none of them had been

Citation: Sarraf DP, Sah BP. Drug Utilisation Pattern in Ear, Nose and Throat Inpatient Department using WHO Prescribing Indicators Nepal J Health Sci. 2021 JanJun;1(1): 21-28 
conducted in Ear, Nose and Throat (ENT) inpatients. Therefore, the study was conducted to assess the drug utilisation pattern in the patients admitted in ENT inpatient department at a tertiary hospital in Eastern Nepal using the World Health Organisation (WHO) prescribing indicators.

\section{METHODS}

A hospital-based descriptive cross-sectional study was conducted in ENT inpatient department at B.P. Koirala Institute of Health Sciences, Dharan, Nepal from February to April 2019. Ethical clearance was obtained from ethical board of B.P. Koirala Institute of Health Sciences (IRC/1248/018). The ENT inpatient department consisted of 36 beds with occupancy of o.7. Patients admitted to the ENT inpatient department at BPKIHS were enrolled in the study. The patients admitted in ENT inpatient department and prescribed at least one drug were included in the study. The patients with human immunodeficiency virus or acquired immunodeficiency syndrome, tuberculosis and psychiatric disorders were not enrolled. A total of 96 patients were included in the study. Random sampling method was used.

A self-designed proforma was prepared based on relevant literature. ${ }^{4,9}$ It consisted of sociodemographic characteristics, diagnosis and drugs prescribed (name of drug, its route of administration, pharmacological classification, generic or brand, single or fixed dose combination). Objective of the study was explained to the study participants in their local language and written informed consent was taken. The data were collected by the principal investigator visited the inpatient department on daily basis and collected the data directly on the proforma after reviewing the case-sheet of the patients. The prescribing physicians were not aware of the study which helped to prevent Hawthorne effect. ${ }^{10}$ No incentives were given to the study participants. The intravenous fluids given to the patients were not considered as drugs.

Data were entered in Microsoft Excel 2010 and analysed using Statistical Package for Social Sciences (version 11.0). The National List of Essential Medicines, fifth revision (NLEM) was used as a basis to determine drugs as generic or brand name. ${ }^{11}$ Two or more drugs that are prescribed in a fixed dose ratio for a given health condition were categorised as Fixed Dose Combination (FDC). Descriptive statistics mean, standard deviation, frequency and percentage and following WHO prescribing indicators were calculated:

(i) Percentage of drugs prescribed by generic name, = number of drugs prescribed by generic name/total number of drugs prescribed $\times 100$.

(ii) Percentage of prescription in which an antibiotic prescribed,

$=$ Number of patient which antibiotic was prescribed/total number of patients $\times 100$.

(iii) Percentage of prescription with an injection prescribed,

=Number of patient in which an injection was prescribed/total number of patients $\times 100$.

(iv) Percentage of drugs prescribed from National List of Essential Medicine (NLEM),

= Number of drugs prescribed from NLEM/total number of drugs prescribed $\times 100$.

(v) Percentage of FDC prescribed $=$ Number of FDC/ total number of drugs $\times 100$.

\section{RESULTS}

Out of 96 patients, 52 (54.17\%) were female, 69 (71.88\%) married and 38 (39.58\%) aged 21-40 years. The age of the patients ranged from 20 days to 77 years. Forty six (47.92\%) suffered from head and neck disease. Hospital stay range from 2-19 days with mean of 5.70 days ( $\mathrm{SD}=2.85$ days) (Table 1 ). 
Table 1: Sociodemographic characteristics of the patients $(n=96)$.

\begin{tabular}{|c|c|c|}
\hline \multicolumn{2}{|c|}{ Variables } & Frequency (\%) \\
\hline Gender & Male & $44(45.83)$ \\
\hline \multirow{3}{*}{ Marital status } & Female & $52(54.17)$ \\
\hline & Married & $69(71.88)$ \\
\hline & Single & $27(28.13)$ \\
\hline \multirow{4}{*}{ Age group (years) } & Upto 20 & $24(25.00)$ \\
\hline & $21-40$ & $38(39.58)$ \\
\hline & $41-60$ & $24(25.00)$ \\
\hline & $>60$ & $10(10.42)$ \\
\hline \multirow{3}{*}{ Residence } & Province 1 & $81(84.38)$ \\
\hline & Province 2 & $11(11.46)$ \\
\hline & India & $4(4.17)$ \\
\hline \multirow{4}{*}{ Educational level } & Illiterate & $26(27.08)$ \\
\hline & Primary & $24(25.00)$ \\
\hline & Secondary & $28(29.17)$ \\
\hline & $\begin{array}{l}\text { Intermediate and } \\
\text { above }\end{array}$ & $18(18.75)$ \\
\hline \multirow{4}{*}{ Diseases classification } & Ear & $18(18.75)$ \\
\hline & Throat & $18(18.75)$ \\
\hline & Nose & $14(14.58)$ \\
\hline & Head and neck & $46(47.92)$ \\
\hline \multirow{3}{*}{ Hospital stay (days) } & $2-5$ & $49(51.04)$ \\
\hline & $6-10$ & $42(43.75)$ \\
\hline & $10-19$ & $5(5.21)$ \\
\hline
\end{tabular}

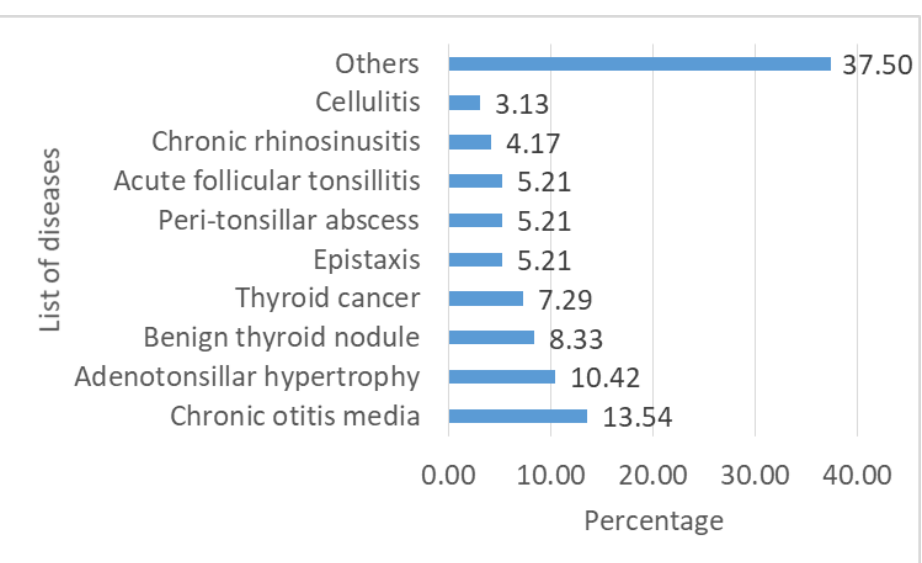

Figure 1: List of diseases diagnosed in the ear, nose and throat inpatients $(\mathrm{n}=96)$.

The most common disease diagnosed was chronic otitis media $(13,13.54 \%)$ followed by adenotonsillar hypertrophy (10, 10.42\%) and benign thyroid nodule $(8,8.33 \%)$ (Figure 1 ).

Table 2: Therapeutic group of drugs prescribed to the patients $(n=390)$.

\begin{tabular}{|l|c|}
\hline \multicolumn{1}{|c|}{ Variables } & Frequency (\%) \\
\hline Non-steroidal anti-inflammatory agents & $112(28.72)$ \\
\hline Systemic antibacterial agents & $97(24.87)$ \\
\hline Proton pump inhibitors & $80(20.51)$ \\
\hline Topical antibacterial + steroids & $32(8.21)$ \\
\hline Histamine H1 blockers & $19(4.87)$ \\
\hline Topical antibacterial agents & $14(3.59)$ \\
\hline Nasal Decongestants & $7(1.79)$ \\
\hline Histamine H2 blocker & $6(1.54)$ \\
\hline Systemic steroidal anti-inflammatory drugs & $6(1.54)$ \\
\hline Others & $14(4.36)$ \\
\hline
\end{tabular}

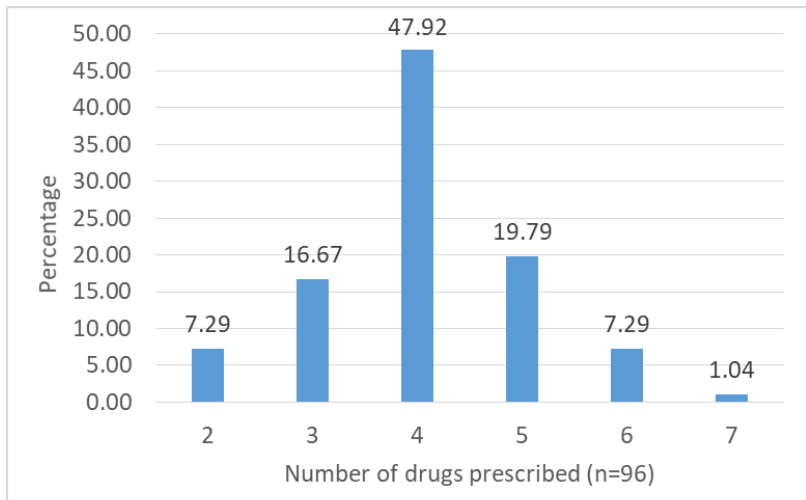

Figure 2: Number of drugs prescribed to the patients $(n=96)$.

A total of 390 drugs were prescribed to 96 patients. Non-steroidal anti-inflammatory agents (112, 28.72\%) were the commonest prescribed group of drugs followed by systemic antibacterial agents $(97,24.87 \%)$ and proton pump inhibitors (80, 20.51\%) (Table 2). Most of the drugs (184, 47.18\%) were prescribed through intravenous injection followed by oral $(151,38.72 \%)$ and topical route $(55,14.10 \%)$. Forty six patients $(47.92 \%)$ were prescribed four drugs followed by five drugs in 19 (19.79\%) and three drugs in 16 (16.67\%) patients. (Figure 2). 
Combination of Ibuprofen and Paracetamol $(77,19.74 \%)$ was the commonest prescribed drug followed by Pantoprazole $(74,18.97 \%)$ and Ceftriaxone $(62,15.90 \%)$ (Table 3$)$.

Table 3: List of individual drugs prescribed in the patients $(n=390)$.

\begin{tabular}{|l|c|}
\hline \multicolumn{1}{|c|}{ Variables } & Frequency (\%) \\
\hline Ibuprofen + Paracetamol & $77(19.74)$ \\
\hline Pantoprazole & $74(18.97)$ \\
\hline Ceftriaxone & $62(15.90)$ \\
\hline Paracetamol & $34(8.72)$ \\
\hline Mupirocin + Beclomethasone & $27(6.92)$ \\
\hline Levocetirizine & $18(4.62)$ \\
\hline Cefpodoxime Proxetil & $16(4.10)$ \\
\hline Povidone-iodine & $10(2.56)$ \\
\hline Oxymetazoline & $7(1.79)$ \\
\hline Esomeprazole & $6(1.54)$ \\
\hline Others & $59(15.13)$ \\
\hline
\end{tabular}

Out of 390 drugs, 97 (24.87\%) were systemic antibacterial agents. Cephalosporin (84, 86.60\%) was the most frequently prescribed systemic antibiotics followed by Penicillins (6, 6.19\%) and Fluoroquinolones (4, 4.12\%) (Figure 3). Ceftriaxone $(62,63.92 \%)$ was the most frequently prescribed systemic antibiotic followed by Cefpodoxime Proxetil (16, 16.49\%) and Amoxicillin + Clavulanic acid (5, 5.15\%) (Table 4).

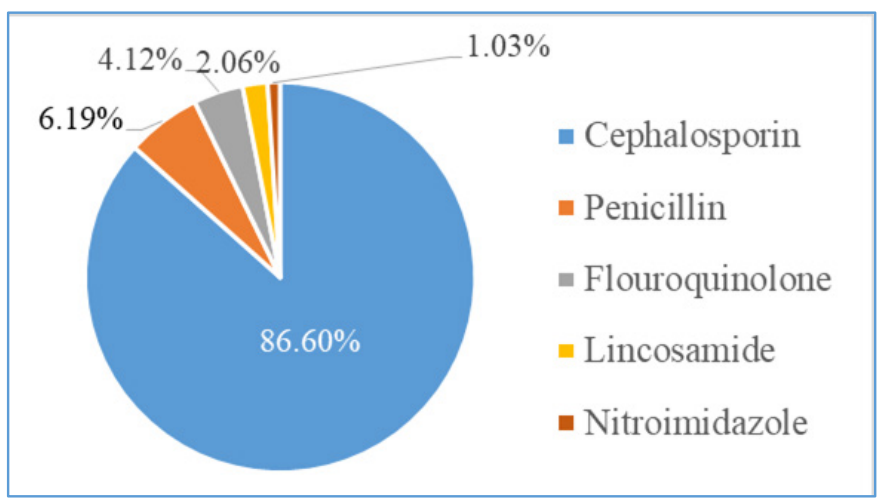

Figure 3: List of therapeutic group of systemic antibacterial agents $(\mathbf{n}=97)$.
Table 4: List of individual systemic antibacterial agents $(n=97)$.

\begin{tabular}{|l|c|}
\hline \multicolumn{1}{|c|}{ Variables } & Frequency (\%) \\
\hline Ceftriaxone & $62(63.92)$ \\
\hline Cefpodoxime Proxetil & $16(16.49)$ \\
\hline Amoxicillin + Clavulanic acid & $5(5.15)$ \\
\hline Cefuroxime Axetil & $3(3.09)$ \\
\hline Ciprofloxacin & $3(3.09)$ \\
\hline Cefoperazone + Sulbactam & $2(2.06)$ \\
\hline Clindamycin & $2(2.06)$ \\
\hline Levofloxacin & $1(1.03)$ \\
\hline Metronidazole & $1(1.03)$ \\
\hline Ampicillin + Cloxacillin & $1(1.03)$ \\
\hline Cefixime & $1(1.03)$ \\
\hline
\end{tabular}

Out of 390 drugs, 55 (14.10\%) were topical drugs. Combination of steroids with antibacterial agent (32, $58.18 \%$ ) was the commonest group of topical drug followed by topical antibacterial agent $(14,25.45 \%)$ and nasal decongestants $(7,12.73 \%)$. The combination of Mupirocin and Beclomethasone $(27,49.09 \%)$ was the most frequently prescribed topical drug followed by Povidone-iodine (10, 18.18\%) and Oxymetazoline (7, 12.73\%) (Table 5). 
Table 5: List of individual topical drugs $(n=55)$.

\begin{tabular}{|l|c|}
\hline \multicolumn{1}{c|}{ Variables } & Frequency (\%) \\
\hline Mupirocin + Beclomethasone & $27(49.09)$ \\
\hline Povidone-iodine & $10(18.18)$ \\
\hline Oxymetazoline & $7(12.73)$ \\
\hline Ofloxacin + Dexamethasone & $5(9.09)$ \\
\hline Ciprofloxacin & $2(3.64)$ \\
\hline Triamcinolone & $1(1.82)$ \\
\hline Benzydamine & $1(1.82)$ \\
\hline Chlorhexidine & $1(1.82)$ \\
\hline Timolol & $1(1.82)$
\end{tabular}

The WHO drug prescribing indicators are displayed in the Table 6. The average number of drugs per prescription was 4.06. None of the drugs were prescribed by generic name. Out of 390, only 118 (30.26\%) drugs were prescribed from the National list of Essential Medicines (fifth revision).

Table 6: The World Health Organaisation drug prescribing indicators.

\begin{tabular}{|l|c|}
\hline \multicolumn{1}{c|}{ Indicators } & Values \\
\hline Average number of drugs per prescription & 4.06 \\
\hline $\begin{array}{l}\text { Percentage of drugs prescribed by generic name } \\
\text { Percentage of prescription in which an antibiotic was prescribed }\end{array}$ & 9 \\
\hline $\begin{array}{l}\text { Percentage of prescription in which an injection was prescribed } \\
\text { Percentage of drugs prescribed from the National List of Essential Medi- } \\
\text { cine }\end{array}$ & 70.83 \\
\hline Percentage of fixed-dose combination (FDC) prescribed & 30.26 \\
\hline
\end{tabular}

\section{DISCUSSIONS}

The study of drug utilisation pattern is conducted to monitor, evaluate, and suggest modifications in the practitioner's prescription habits so as to make patient care safe and cost-effective. ${ }^{12}$ It is an ongoing and systemic investigation which provide feedback to the prescribers. The periodic auditing of prescription patterns ensures the rational use of drugs as it detects early signals of irrational use. ${ }^{9}$ The present study has provided a highly representative data which would aid the prescribers in rational use of drugs to improve the quality of care in hospitalised patients. In present study, average number of drugs per prescriptions was found to be 4.06 which was higher than the recommended value. ${ }^{13}$ Similar findings was also reported by Abidi et al. ${ }^{14}$ Average number of drug per prescription is an important indicator for assessing rationality of prescription. Hence, it is preferable to keep the mean number of drugs per prescription as low as possible since higher number of drugs may lead to increased risk of drug interactions, development of resistance and increased cost of the treatment. ${ }^{15,16}$

The WHO indicates that percentage of prescription with an antibiotic prescribed should be less than $30 \% .^{13}$ Antibiotics constituted about $96 \%$ of the prescription prescribed in this study, indicating the high prescription of antibiotics in the hospital. A lower percentage of antibiotics were prescribed in a study by Yilma et al. ${ }^{17}$ The findings indicated that prescribers should adhere to the guidelines to prescribe antibiotics appropriately and rationally to the patients. Culture and sensitivity test should be performed time to time to know the susceptibility to the frequently 
used antibiotics. The WHO proposes that optimally all medicines (100\%) should be prescribed by generic names. ${ }^{13}$ In this study, it was found that none of the drugs were prescribed by generic name. This could be due to the influence of non-availability of generic drugs in the market and drug promotional activities by medical representatives. Prescribing by generic names may reduce overall expenditure on drugs especially on newer drugs. The government should ensure the availability of generic drugs in the hospitals which help to reduce the cost of the drug therapy.

The WHO has proposed that an optimal value for percentage of prescription with an injection prescribed should be less than 20\%. ${ }^{13}$ In the present study, more than two third of the prescription had injectable drug. An increase in the rate of use of injections might highlight emergency issues as injections are crucial dosage forms in these situations because of their fast onset of action. However, excessive use of injections may lead to physiological and psychological pain and increase in cost of the therapy. Less than one third of the drugs were prescribed from NLEM which was higher than the recommended by the WHO. Ideally all drugs should be prescribed from the NLEM as per the guidelines. ${ }^{13}$ However, the prescriber may prescribe the drugs which are not in the NLEM at tertiary hospital by considering risk-benefit ratio.

Non-steroidal anti-inflammatory agents and systemic antibacterial agents were prescribed in more than half of the patients. Combination of Ibuprofen and Paracetamol was the commonly prescribed drug. Approximately one out of four patients were prescribed one systemic antibiotic and Cephalosporin was the most frequently prescribed systemic antibiotics. Similar findings were also reported by Ain et al. in an Indian study.$^{18}$ Ceftriaxone was the most frequently prescribed systemic antibiotic in this study. In contrast to this finding, Amoxicillin + Clavulanic acid was the commonly prescribed antibiotic in another study. ${ }^{18}$ Majority of the prescriptions included Cefotaxime (39.62\%) in another study as well. ${ }^{19}$ These differences might be due to an increase in local antibiotic resistance that encourages the prescribers to choose a broader and safer antibiotic. It is extremely important that medical institutions and other hospitals should have an antibiotic policy to ensure the best choices by the prescribers.
The finding of the present study illustrated that an improvement is required in the prescribing pattern of drugs in the ENT inpatient department. Hospital based therapeutic drug committee should be established for the safe and effective use of drugs in the hospital. Educational programs on rational use of drugs should be conducted frequently to change the attitude of prescribers for effective patient care and to promote rational use of drugs. ${ }^{20}$

The present study has some limitations. The study has small sample size. Cost of therapy was not analysed. The study was carried out for a three month period and therefore we could not assess the seasonal variations in drug utilisation pattern. The study was restricted to a single department of a hospital and therefore, the study findings could not be generalised to the other hospital or the whole country.

\section{Conclusions}

In the present study prescribing practices of essential medicines, generic drugs, antibiotics and injectable drugs showed deviation from the standard recommended by the WHO. The prescribers should be motivated to enhance prescription of drugs by generic names and from NELM. The study findings would give the feedback on the use of drugs in the hospitalised patients and would help to formulate the hospital guidelines for rational use of drugs. The study findings highlights the need of continue medical education to train the prescribers to adhere to the WHO standards for prescribing. Periodic evaluation of drug utilisation pattern should be carried out to ensure rational drug therapy.

\section{ACKNOWLEDGEMENT}

We would like to thank Dr. Shashi Keshwar, Department of oral pathology, College of Dental Surgery, B.P. Koirala Institute of Health Sciences, Dharan, Nepal for reviewing the manuscript.

\section{Conflict of interest: None}




\section{REFERENCES}

1. Promoting rational use of medicines: core components. World Health Organisation, 2002. Accessed on December 7, 2020. [Full Text]

2. Kshirsagar M, Langade D, Patil S, Patki P. Prescribing patterns among medical practitioners in Pune, India. Bull World Health Organ. 1998;76(3):271-5. [PubMed | Full Text ]

3. Introduction to drug utilisation research. World Health Organisation, Norway, 2003. Accessed on December 7, 2020. [Full Text]

4. Mittal N, Mittal R, Singh I, Shafiq N, Malhotra S. Drug utilisation study in a tertiary care center: recommendations for improving hospital drug dispensing policies. Indian J Pharm Sci. 2014;76(4):308-14

. [PubMed | Full Text ]

5. Sarraf DP, Rauniar, GP, Misra A. Drug utilisation pattern in four major wards of a tertiary hospital in Eastern Nepal. Health Renaissance. 2017; 13(2):50-65. [ Full Text | DOI]

6. Shankar PR, Partha P, Dubey AK, Mishra P, Deshpande VY. Intensive care unit drug utilisation in a teaching hospital in Nepal. Kathmandu Univ Med J (KUMJ). 2005;3(2):130-7. [PubMed | Full Text ]

7. Shankar PR, Dubey AK, Rana MS, Mishra P, Subish P, Vijaya Bhaskar P. Drug utilisation with special reference to antimicrobials in a sub-healthpost in Western Nepal. JNHRC. 2005;3(2):65-9. [Full Text]

8. Upadhaya D, Mishra P, Shankar PR, Partha P, Dubey AK. Drug utilisation in Medical inpatients. JNHRC. 2008;4(1):56-62. [Full Text]

9. How to investigate drug use in health facilities: selected drug use indicators. World Health Organisation, 1993. Accessed on May 21, 2021. [Full Text]

10. Mangione-Smith R, Elliott MN, McDonald L, McGlynn EA. An observational study of antibiotic prescribing behavior and the Hawthorne effect. Health Serv Res. 2002;37:1603-23. [PubMed | Full Text | DOI]

11. Essential Drug List. Department of Drug Administration, Nepal, 2017. Accessed on 21 May 2021[Full Text]

12. Shankar RP, Partha P, Shenoy NK, Easow JM, Brahmadathan KN. Prescribing patterns of antibiotics and sensitivity patterns of common microorganisms in the Internal Medicine ward of a teaching hospital in Western Nepal: A prospective study. Ann Clin Microbiol Antimicrob. 2003;2:7. [PubMed | Full Text | DOI]

13. Using Indicators to Measure Country Pharmaceutical Situations. World Health Organisation, Geneva, 2006. Accessed May 7, 2021. [Full Text]

14. Abidi A, Gupta S, Kansal S, Ramgopal. Prescription auditing and drug utilisation pattern in a tertiary care teaching hospital of western UP. Int J Basic Clin Pharmacol. 2012;1(3):184-90. [Full Text]

15. Das BP, Sethi A, Rauniar GP, Sharma SK. Antimicrobial utilisation pattern in outpatient services of ENT department of tertiary care hospital of Eastern Nepal. Kathmandu Univ Med J (KUMJ). 2005;3(4):370-5. [Full Text ]

16. Guthrie B, Makubate B, Hernandez-Santiago V, Dreischulte T. The rising tide of polypharmacy and drug-drug interactions: population database analysis 1995-2010. BMC Med. 2015;13:74. [PubMed | Full Text | DOI]

17. Yilma Z, Liben M. assessment of drug prescription pattern in Mekelle general hospital, Mekelle, Ethiopia, using World Health Organisation prescribing indicators. Biomed Res Int. 2020;2020:3809157. [PubMed | Full Text | DOI]

18. Ain MR, Shahzad N, Aqil M, Alam MS, Khanam R. Drug utilisation pattern of antibacterials used in 
1. ear, nose and throat outpatient and inpatient departments of a university hospital at New Delhi, India. J Pharm Bioallied Sci. 2010 ;2(1):8-12. [PubMed | Full Text | DOI]

2. Isaac S, Jayakumari S, Lekshmi RSS. A Prospective study on the drug prescribing pattern of antibiotics in the ears, nose and throat department of a tertiary care hospital. Research J Pharm Tech. 2019;12(12):6001-6. [Full Text | DOI]

3. Desalegn AA. Assessment of drug use pattern using WHO prescribing indicators at Hawassa University Teaching and Referral Hospital, south Ethiopia: a cross-sectional study. BMC Health Serv Res. 2013;13:170. [PubMed | Full Text | DOI]

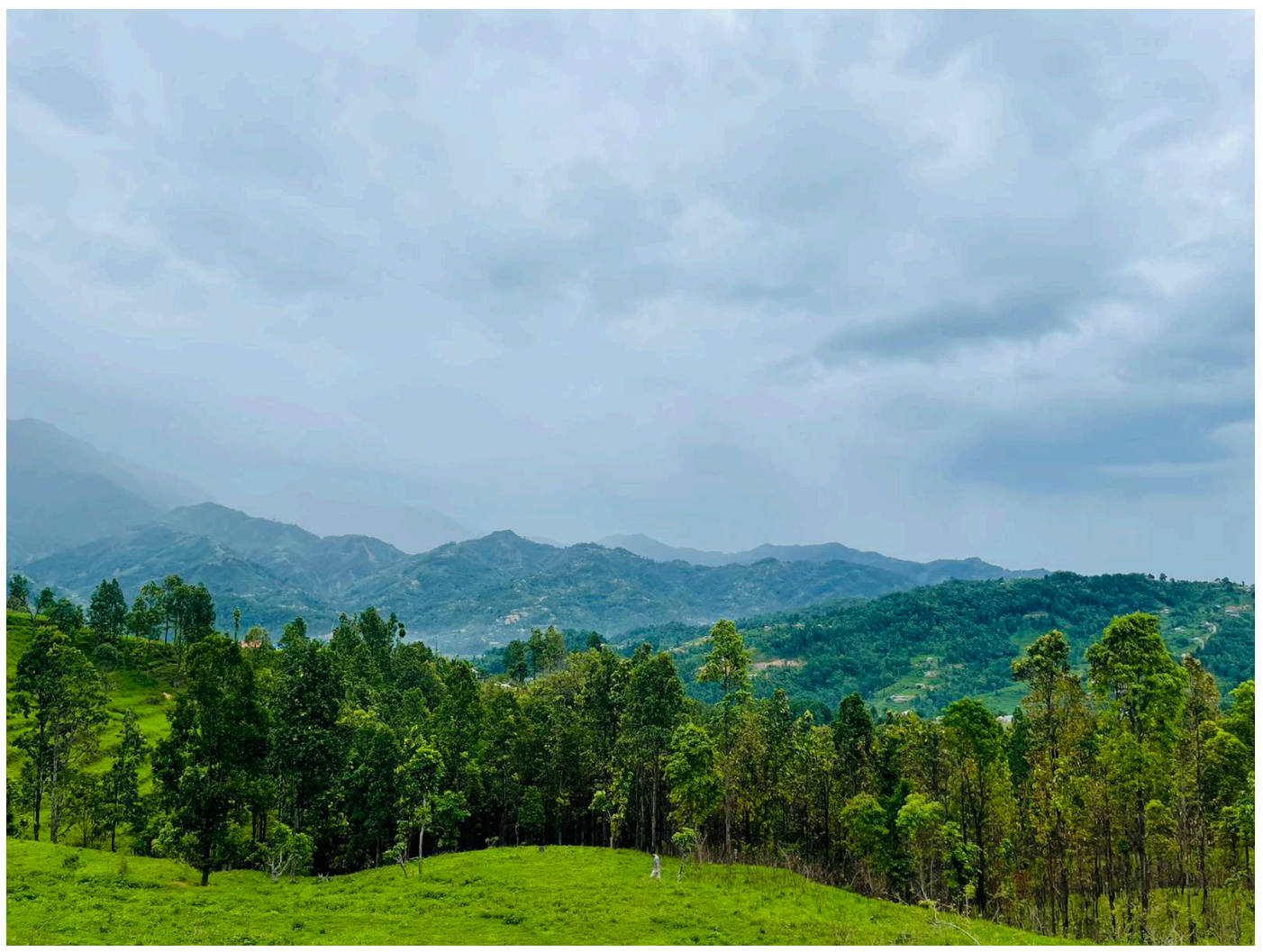

At the top of Chure Hills

-Nisha Dhungana, MD 